\section{Transfer of a dominant gene for resistance to eyespot disease from a wild grass to hexaploid wheat}

\section{G. Doussingult}

INRA, Station d'Amelioration des Plantes, BP29, 35650 Le Rheu, France

\section{A. Delibes, R. Sanchez-Monge \& F. Garcia-Olmedo}

Departmento de Bioquímica, ETS Ingenieros Agrónomos, Madrid-3, Spain

Eyespot disease, caused by the fungus Pseudocercosporella herpotrtcholdes, is responsible for considerable lodging and reductions of yield in extensive areas of whest cultivation in North and South America, Europe, New Zealand, Australia and Africa'. The level of resistance of wheat cultivars is too low, even among the less susceptible ones (that is, Cappelle Desprez and Cerco) and no genes for resistance have to date been characterized in any species. Sprague ${ }^{2}$ found a high level of resistance to this disease in the wild grass Aegilops ventricosa and several workers have attempted its transfer to cultivated wheat with only partial success ${ }^{-s}$. We report here a major dominant gene for resistance, which has been transferred from tetraploid Ae. ventricosa (genomes $D^{\circ} D^{v} M^{v} M^{v}$ ) to hexaplold wheat, Triticum aestivum ( $A A B B D D$ ), using tetraploid whent, Triticum turgidum ( $A A B B$ ), as a 'bridge' species.

The breeding scheme is represented in Fig. 1. A hybrid was obtained between the donor and the bridge species, which was male sterile, probably due to the lack of homology between the genome complements of its progenitors. The meiosis of this hybrid was irregular and the egg cells generated presumably had a wide range of chromosome combinations. Certain of these egg cells yielded seeds when the hybrid was pollinated with pollen from hexaploid wheat. Plants from these seeds were fertile and, after repeated selfing, stable lines with $\mathbf{4 2}$ chromosomes (H-93-1 to H-93-70) were derived from them. These lines were screened for biochemical markers encoded by genes located in the $D^{*}$ and $M^{*}$ genomes of $A e$, ventricosa ${ }^{6-8}$. Due to the partial homology of the $D^{v}$ genome of the donor and the $D$ genome of the recipient, markers associated with the $D^{v}$ genome appeared at high frequencies $(30-60 \%)$. Genes from

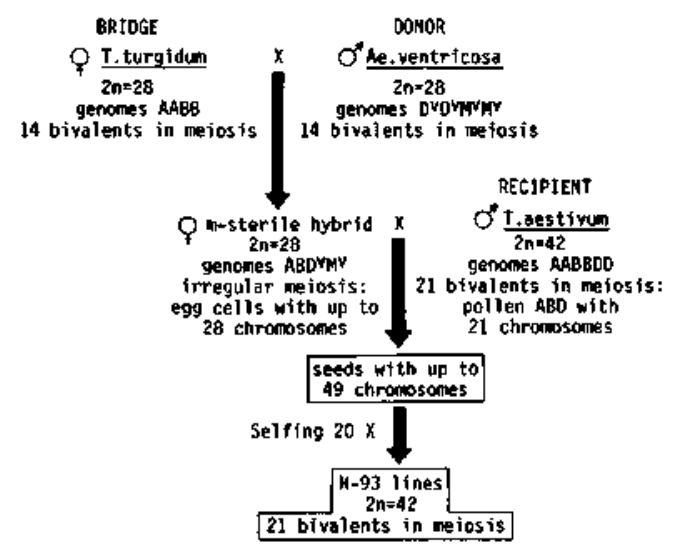

Fig. 1 Triticum turgidum H-1-1, Aegilops ventricosa AP-1 and $T$. aestivum cv. Almantense $\mathrm{H}-10-15$ were crossed according to this breeding scheme. Seeds resulting from these crosses were selfed repeatedly until a wide range of stable morphological types had been obtained. After stability had been achieved, somatic chromosome numbers were counted in the root tips of germinating seeds stained by the Feulgen procedure. Most of the lines had the euploid number of chromosomes $(2 n=42)$ at that stage. The distribution among these lines of biochemical markers corresponding to the $D^{v}$ and $M^{v}$ genomes of the donor species was then investigated ${ }^{6,7}$. Subsequently, susceptibility to eyespot disease was tested in the same lines.

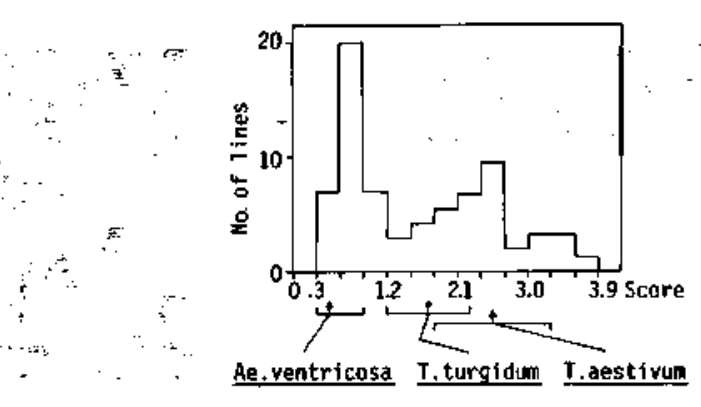

Fig. 2 Susceptibility to Pseudacencosporella herpotrichoides (score: average number of leaf sheaths infected per plant) of $\mathrm{H} \cdot \mathbf{9 3}$ lines (H-93-1 to H-93-70) and of the parental material from which they were derived. The arrows indicate the average value for each of the parental species and the brackets the range of values that do not differ significantly from those averages $(P<0.5 \%)$. Scores for 33 of the lines did not differ significantly from that of Aegilops ventricosa AP-1 and were significantly lower than that of Triticum turgidum $\mathrm{H}-1-1$, the most resistant of the two wheat progenitors. Only four lines were more susceptible than $T$. aestivum cv. Almatense H-10-15.

the $M^{v}$ genome, which is not homologous to any of the hexaploid wheat genomes $(A, B$ or $D)$, generally appeared at lower frequencies $(<4 \%)$, although one such gene did appear at a higher frequency $(31 \%)^{7}$. A study of meiosis in hybrids between H-93 lines and the hexaploid wheat, together with the biochemical data, indicated that genes from the donor had been incorporated into the $\mathrm{H}-93$ lines both by chromosomal substitution and by recombination ${ }^{6,7}$. Attempts at direct hybridization between $A e$. ventricosa and hexaploid wheat had been unsuccessful at the time the initial crosses described here were performed. The only such hybrid subsequently obtained was male sterile? This hybrid would probably have been a less adequate intermediate in the gene transfer because it carried all the hexaploid wheat genomes $(A, B$ and $D)$ and, when rescued with $A B D$ pollen, would have had a greater tendency to eliminate the alien genetic material while selecting for the euploid chromosome number $(2 n=42)$.

Table 1 Susceptibility to eyespot of line H-93-70 and its progenitors

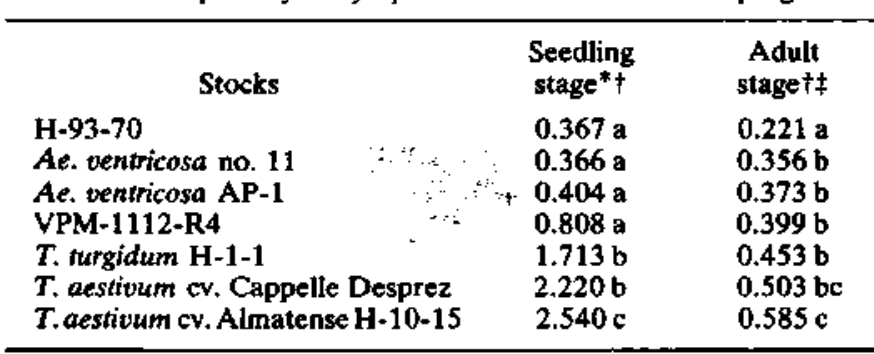

In addition to line H-93-70 and its progenitors, the following stocks were tested: Accession no. 11 (Rennes) of Ae. ventricosa, line VPM$1112-\mathbf{R} 4$, which is a derivative of line VPM1, and cultivar Cappelle Desprez, which is the less susceptible hexaploid wheat. Line VPM1 was obtained by crossing a synthetic aljoploid $(2 \times[\%$ Ae. ventricosa $\times$ of $T$. persicum ]; genomes $A A B B D^{\circ} D^{v} M^{5} M^{v}$ ) with a hexaploid wheat ${ }^{3}$ and has a level of resistance which is intermediate between those of Ae. ventricosa and wheat.

* The average numbers of leaf sheaths attacked per plant are given. Three replicates of 50 seeds each were sown in a plastic tunnel and inoculated with mycelium which had been obtained by in vitno culture and ground into a powder ${ }^{8}$.

$\dagger$ Duncan's multiple range test was used; numbers followed by different letters in the same column differ significantly $(P<0.5 \%)$; variation coefficients were $22 \%$ and $24.8 \%$ in the tests at the seedling and the adult stages, respectively.

\$ The proportions of stems with more than $50 \%$ of section attacked are given. Three replicates of 50 seeds each were sown in the field and inoculated by spraying a suspension of the fungus previously cultivated on oat grains 8 . 
Table 2 Inheritance of resistance to eyespot disease in crosses of line H-93-70 with $T$. aestivum cv. Almatense H-10-15

\begin{tabular}{|c|c|c|c|c|c|c|c|c|c|c|}
\hline \multirow{3}{*}{ 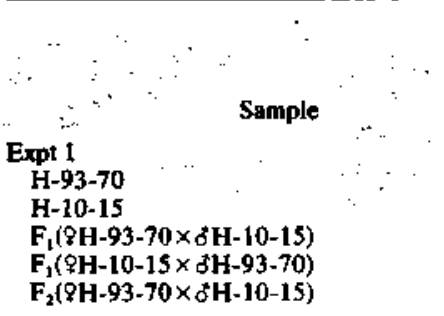 } & \multirow{3}{*}{\multicolumn{2}{|c|}{$\begin{array}{l}\text { Cyloplasmic } \\
\text { background } \\
\text { T. turgidum } \\
T \text {. aestioum } \\
T . \text { turgidum } \\
T \text {. aestivam } \\
T \text {. turgidum }\end{array}$}} & \multicolumn{3}{|c|}{$\begin{array}{c}\text { No. of plants } \\
\text { No. of leaves } \\
\text { affected* }\end{array}$} & \multicolumn{2}{|c|}{$\begin{array}{l}\text { Mean of no. of } \\
\text { leaves affected }\end{array}$} & \multicolumn{3}{|c|}{$\begin{array}{l}\text { Mycelium typet } \\
\text { (\% plants) }\end{array}$} \\
\hline & & & Tested & $0-2$ & $3-5$ & Observed & Expected ${ }^{\dagger}$ & $(-)$ & (v) & (m) \\
\hline & & & $\begin{array}{r}30 \\
30 \\
30 \\
30 \\
178\end{array}$ & $\begin{array}{r}27 \\
3 \\
27 \\
23 \\
128\end{array}$ & $\begin{array}{r}3 \\
27 \\
3 \\
7 \\
50\end{array}$ & $\begin{array}{l}1.60 \\
3.33 \\
1.90 \\
2.07 \\
2.05\end{array}$ & • $\cdots$ & $\begin{array}{r}43.3 \\
0.0 \\
13.3 \\
23.3 \\
25.8\end{array}$ & $\begin{array}{r}56.7 \\
0.0 \\
83.3 \\
53.4 \\
65.2\end{array}$ & $\begin{array}{r}0.0 \\
100.0 \\
0.0 \\
23.3 \\
9.0\end{array}$ \\
\hline $\begin{array}{l}\text { Expt } 2 \\
\text { F }_{2}(\$ H-10-15 \times d H-93-70) \\
(9 H-10-15 \times d H-93-70) \times \delta H-93-70 \\
(9 H+10-15 \times \delta H-93-70) \times \delta H-10-15\end{array}$ & & $\begin{array}{l}\text { T. aestivum } \\
T . \text { aestivam } \\
\text { T. aestivam }\end{array}$ & $\begin{array}{r}116 \\
89 \\
88\end{array}$ & $\begin{array}{l}86 \\
85 \\
40\end{array}$ & $\begin{array}{r}30 \\
4 \\
48\end{array}$ & $\begin{array}{l}2.22 \\
1.69 \\
2.68\end{array}$ & $\begin{array}{l}2.26 \\
1.83 \\
2.70\end{array}$ & $\begin{array}{l}2.6 \\
5.6 \\
1.1\end{array}$ & $\begin{array}{l}69.0 \\
88.8 \\
42.0\end{array}$ & $\begin{array}{r}28.4 \\
5.6 \\
56.8\end{array}$ \\
\hline $\begin{array}{l}\text { Expt } 3 \\
\text { H-93-70 } \\
\text { H-10-15 } \\
F_{f}(8 H-93-70 \times \delta H-10-15) \\
(\$ H-93-70 \times \delta H-10-15) \times \delta H-93-70 \\
(9 H-93-70 \times \delta H-10-15) \times \delta H=10-15\end{array}$ & & $\begin{array}{l}T . \text { turgidum } \\
T . \text { aestivum } \\
T . \text { turgidum } \\
T \text {. turgidum } \\
T \text {. turgidum }\end{array}$ & $\begin{array}{r}95 \\
99 \\
100 \\
98 \\
97\end{array}$ & $\begin{array}{l}82 \\
15 \\
73 \\
80 \\
49\end{array}$ & $\begin{array}{l}13 \\
84 \\
27 \\
18 \\
48\end{array}$ & $\begin{array}{l}1.75 \\
3.22 \\
2.04 \\
1.91 \\
2.57\end{array}$ & $\begin{array}{l}1.90 \\
2.63\end{array}$ & $\begin{array}{r}45.3 \\
3.0 \\
13.0 \\
33.7 \\
9.2\end{array}$ & $\begin{array}{r}53.6 \\
6.1 \\
86.0 \\
65.3 \\
64.0\end{array}$ & $\begin{array}{r}2.1 \\
91.0 \\
1.0 \\
1.0 \\
26.8\end{array}$ \\
\hline
\end{tabular}

$F_{1}, F_{2}$ and backcross generations were obtained with two different cytoplasmic genetic backgrounds: that of line $\mathrm{H}-93-70$, which had been originally contributed by $T$. turgidum H-1-1 (see Fig. 1), and that of the T. aestivum cv. Almatense H-10-15. Plants were tested at the seedling stage.

* Plants were classified into resistant (two or less leaf sheaths infected) and susceptible (three to five leaf sheaths infected). The observed segregation in each of the $F_{2}$ generations did not differ significantly $\left(X^{2} \ll \chi_{d t-1, P-0.0 s}^{2}=3.84\right)$ from the segregation 3 resistant/1 susceptible expected for a dominant gene. The observed segregations in each of the backerosses to the susceptible parent (H-10-15) did not differ by the same criterion from the segregation 1 resistant/1 susceptible expected for a dominant gene.

$t$ Expected means for $F_{2}$ generations and backcrosses were calculated from the observed means of the progenitors and the appropriate $F_{1}$ generation from the same experiment, except for experiment 2 , in which the data from experiment 1 were used.

$\$$ No stroma observed (- type); spotted and dark brown mycelium (v type); abundant black mycelium ( $m$ type).

A high proportion of the $\mathrm{H}-93$ lines were found to be highly resistant to the disease (Fig. 2 and ref. 8) and line H-93-70 was selected for further study because of its good performance in tests for resistance both at the seedling and at the adult stages (Table 1). Reciprocal crosses ( $F_{1}$ and $F_{2}$ generations) and backcrosses were obtained from line $\mathrm{H}-93-70$ and the recipient $T$. aestivum cultivar Almantense $\mathrm{H}-10-15$ (hereafter designated $\mathrm{H}-10-15)$ and tested for resistance. Two types of observation were made: a quantitative one, the number of leaf sheaths affected per plant, and a qualitative one, the type of mycelium. The pathogen, which is relatively nonspecific, produces two types of mycelium, depending on the host ${ }^{10-12}$ : on susceptible plants, the mycelium is abundant between the leaf sheaths, and is coloured black ( $m$ type); on resistant plants with $A e$, ven tricosa cytoplasm the mycelium is spotted and dark-brown ( $v$-type). Leaf sheaths of resistant plants are invaded more slowly than those of susceptible ones and often they are not invaded beyond the first leaf, so that no stroma can be observed. Sometimes the distinction between the two types of mycelia is not clear-cut.

Table 2 summarizes the results of these tests. In our experimental conditions, close to $90 \%$ of the H-93-70 plants tested had two or less leaf sheaths infected, whereas a similar proportion of plants from $\mathrm{H}-10-15$ had from three to five leaf sheaths infected. Both the pattern of segregation and the average number of leaf sheaths penetrated in $F_{1}, F_{2}$ and backcross generations indicated that resistance was inherited as though determined by a single mendelian factor (PchI), which showed almost complete dominance.

In $F_{1}, F_{2}$ and backcross generations, the proportion of plants with black mycelia ( $m$ type) was greater when the cytoplasmic genetic determinants (mitochondrial and chloroplast genomes), which are maternally inherited, were contributed by $T$, aestivum cv. Almatense $\mathrm{H}-10-15$ than when the source was $\mathrm{H}-93-70$, whose mitochondrial and chlotoplast genomes were donated by $T$. turgidum $\mathrm{H}-1-1$, the bridge species used as a female in the transfer scheme (Table 2). The proportions of mycelium types seem to be more variable in response to environmental conditions, or in relation to plant vigour, when the $P c h 1$ gene is expressed in the $\mathrm{H}-10-15$ cytoplasmic genetic background. This effect is less conspicuous when resistance is assessed by the number of leaves penetrated. A similar effect on resistance to that reported here for the $T$. turgidum H-1-1 cytoplasmic genetic background has previously been described for the $A e$. ventricosa background ${ }^{10-12}$.

To investigate whether the $P$ ch 1 gene in H-93-70 was integrated in a chromosome capable of pairing and recombination with wheat chromosomes, meiosis of the hybrid o H-93-70 $\$ \mathrm{H}-10-15$ was studied and was found to be quite regular: $20.70 \pm 0.02$ bivalents at metaphase $I$ in the hybrid, versus $20.82 \pm 0.05$ bivalents in $\mathrm{H}-93-70$ and $20.98 \pm 0.02$ bivalents in $\mathrm{H}-10-15$ (at least 5 plants and 50 cells were analysed in each case; differences between the hybrid and the progenitors were not significant). These observations exclude the presence in H-93-70 of whole chromosomes or large chromosomal segments non-homologous to wheat chromosomes and indicate that the Pch1 gene can be introduced by recombination into other wheats. The present data cannot distinguish whether the $P c h 1$ gene has been transferred from the $M^{\circ}$ or the $D^{\circ}$ genomes of Ae. ventricosa because, although resistance was transferred with the high frequency expected of a $D^{\circ}$ gene, recombination between $D^{v}$ and $M^{v}$ chromosomes before the transfer has been suspected in Ae. ventricosa AP-1 $1^{6,7,12}$.

The chromosomal locations of resistance factors in cultivar Roazon, whose intermediate level of resistance has been acquired from line VPM1 (see Table 1 legend), have been assigned to chromosomes $7 \mathrm{~A}, 2 \mathrm{~B}, 5 \mathrm{D}$ and $7 \mathrm{D}$, the main effect being associated with the last chromosome. It will be of interest to investigate whether gene Pchl in H-93-70 is also located in chromosome 7D.

Law et al. ${ }^{13}$ demonstrated that more than one chromosome (gene) was involved in the differences in susceptibility between Cappelle, the most resistant wheat cultivar, and other wheat cultivars. They detected both positive and negative effects that were dependent on the genetic background. The higher level of resistance attained in the present case, as compared with previous attempts ${ }^{3-5}$, can be explained in terms of the monogenic nature of the resistance transferred and of the nature of the genetic background, nuclear as well as cytoplasmic, into which the transfer was made: $T$. aestivum cv. Almatense $\mathrm{H}-10-$ 15 is almost as resistant as Cappelle, and $T$. turgidum $H-1-1$, the cytoplasm donor, is even more resistant.

Apart from contributing to our understanding of the genetic control of resistance to eyespot disease, the gene reported here 
should be immediately useful in converting susceptible wheat cultivars to this major disease into resistant ones.

This paper is dedicated In Memoriam to M. Alonso Peña who carried out the initial crosses. We acknowledge the technical assistance of $\mathrm{H}$. Joualt, C. Pérez-Pellón and C. Rojas.

Received 14 February; eccepted 25 April 1983.

1. Wiese, M. V. Compendium of Whear Diseases, 46-47 (American Phytopentholodixal Society, St Paul, 1977).

2. Sprague, R. I. agric, Res. $53,659-670$ (1936).

3. Maia, N. C.x. Aced agric. F. 53, 149-154 (1967).

4. Kimber, G. J. agric. Sel. 68, 373-376 (1967).
5. Dosba, F. Doussinault, G. in Phoc. 8th EUCARPIA Congr., Madrid, 99-107 (edts Sánchez-Monge, E. \& Garcia-Oimedo, F) (EUCARPIA, 1977)

6. Delibes, A. \& Garcia-Olmedo, F. in Proc, 4th Int. Wheas Genetics 5ymp., 161-166 leds Sears E. R. \& Sears L. M. S.) (A Aric. Exp. Stn, Univ. Missouri, Columbia, 1973).

7. Delibes, A., Sánchez-Monec, R. \& García-Olmedo, F. in Proc. Bth EUCARPIA Congr. Madrid, 81-89 (eds Sánchez-Monge, E. \& Garcí-OMmedo, F.) (EUCARPIA, 1977) 8. Delibes, A., Dosba, F., Doussinault, G., Garcia-Olmedo, F. \& Sánchez-Monge, R. Proc. Bih EUCARPIA Congr., Madrid, 91-97 (eds Sánchez-Monge, E. \& Gurcía-Olmedo, F.) $91-97$ (EUCARPIA, 1977)

9. Dosba, F. Ceuderon, I. Wheat Inf. Serv. 35, 22-23 (1972).

10. Jabier, J., Doussinault, G. Dorba, F. B Bourgeois, F. Proc. Sth int Where Genetics Symep. (ed. Remanujan S, 437-440 (Indian Soc, Genet, end Plant Breeding, New Delhi, 1978) Dosbe, F. Doussipanlt, G. \& Rivosl, R. Proc, Sth int. Wheat Genetics Symp (ed. Ramanujan, S) 332-337 (Indian Soc Genet and Plant Breedine New Dethi 1978).

12. Delibes, A., Otero, C., García-Olmedo, F. \& Dosba, F. Theor. appl. Genet. 60, 5-10 (1981) 13. Low, C. N., Scott, P. R., Wortand, A. J. 2 Hollins, T, W. Genet. Res. Camb. 25, 73-79 (1976). 